\title{
Breve análisis del ceremonial para la fiesta Nacional del 16 de septiembre de 1866, de Maximiliano de Habsburgo segundo emperador de México.
} \author{
Mexico. \\ José Gómez Huerta Suárez ${ }^{1}$ \\ Instituto Colimense de las Mujeres México \\ ppghuerta@gmail.com
}

Brief analysis of the ceremonial for the National holiday of September 16 1866, of Maximilian of Habsburg second emperor of

Recepción: 18/12/2018 Revisión: 12/02/2019 Aceptación: 12/02/2019 Publicación: 01/06/2019

\section{Resumen}

En este artículo se analiza la festividad más importante de México, en el periodo del Archiduque Maximiliano de Habsburgo. La búsqueda de los conservadores mexicanos de un candidato monárquico acorde con sus intereses. La llegada de Maximiliano de Habsburgo y de su esposa Carlota a México con el apoyo del ejército francés pero esto no supondrá el fin del conflicto mexicano entre los conservadores monárquicos y los liberales republicanos.

Palabras Claves: Maximiliano de Habsburgo, Corte, Napoleón III, Festividad.

\section{Absytract}

In this article I analyze the most important festivity in Mexico, in the period of Archduke Maximilian of Habsburgo second Mexican Empire. The arrival of Maximilian of Habsburgo and his wife Carlota to Mexico with the support of the French army not mean the end of conflict between the Mexican monarchist's conservatives and liberal Republicans.

KEYWORDS: Habsburgo Maximilian, Court, Napoleon III, festivity

\footnotetext{
${ }^{1}$ Doctor en derecho por la Universidad Nacional de Educación a Distancia (UNED) España. Master en
} Protocolo por la UNED. 


\section{Sumario}

1. INTRODUCCIÓN.

2. EL SEGUNDO EMPERADOR EN MÉXICO, MAXIMILIANO DE HABSBURGO.

3. ANÁLISIS DEL CEREMONIAL, PARA LA FIESTA NACIONAL DEL 16 DE SEPTIEMBRE DE 1866.

4. FUNCIONES DEL GRAN MAESTRO DE CEREMONIAS Y EL SERVICIO DE LAS CEREMONIAS.

5. PUNTOS FINALES.

6. BIBLIOGRAFÍA.

\section{INTRODUCCIÓN}

El 10 de abril de 1864 se presentaron en el Castillo de Miramar, los comisionados mexicanos José María Gutiérrez de Estrada, Joaquín Velásquez de León, Ignacio Aguilar, José Manuel Hidalgo y otros, ante el archiduque de Austria, Fernando Maximiliano de Habsburgo, para entregarle los votos de la Junta de Notables que lo habían elegido como emperador de México².

La Junta de Notables se había formado por decisión del comandante francés Federico Forey, jefe del cuerpo expedicionario en México, quien emitió un decreto, el 16 de junio de 1863, en el cual se desconocía al gobierno de Benito Juárez García y se ordenaba la formación de la Junta Superior de Gobierno para decidir la forma de gobierno definitivo de México y la dirección de los asuntos del país.

Hijo del archiduque Francisco Carlos de Austria, hermano menor del emperador Francisco José I de Austria, esposo de la princesa Carlota Amalia, hija del rey Leopoldo I de Bélgica y proveniente de una Casa Real defensora del absolutismo monárquico, convencido de su aceptación por parte del pueblo mexicano, Maximiliano de Habsburgo aceptó la corona de México, ofrecida por la Junta de Notables. En su aceptación oficial de la Corona, expresó:

\footnotetext{
${ }^{2}$ Fernando Maximiliano era hijo del Archiduque Francisco Carlos y de la Archiduquesa Sofía, y se casó con la princesa María Carlota Amalia, en 1857, ésta hija de Leopoldo I, rey de Bélgica, y de la princesa Luisa de Orleáns.
} 
"Acepto el poder constituyente con que ha querido investirme la nación, cuyo órgano sois vosotros, pero sólo lo conservaré el tiempo preciso para crear en México un orden regular y para establecer instituciones sabiamente liberales."

Sus ideas le generaron dificultades para mantener alianzas con la Santa Sede, su representante el Monseñor Pedro Francisco Meglia, se negó a aceptar la tolerancia de todos los cultos, pero siendo la religión del Estado, la católica; el sostenimiento del culto y sus ministros por el Estado; la gratuidad de los ministerios religiosos; la cesión de los bienes eclesiásticos al gobierno; el Patronato Imperial como el que se había dado con el reino español; el restablecimiento de las órdenes religiosas por el Papa de acuerdo con el emperador, la jurisdicción del clero sólo en causas de fe y del fuero interno, el Registro civil llevado por los sacerdotes como funcionarios públicos y los cementerios regulados por la autoridad civil y común a los católicos y disidentes.

Maximiliano empezó su gobierno con un programa de corte liberal que poco tocaría las Leyes de Reforma Juaristas, lo que generó que se le retiraran simpatías por parte de los grupos conservadores. De enero a octubre de 1865, dictó leyes que versaban sobre el pase imperial para los documentos pontificios; la tolerancia de cultos; la revisión de las operaciones de desamortización y nacionalización de los bienes eclesiásticos; la ley de cementerios, la ley del registro civil y el Reglamento de su corte (1866) que analizaremos más adelante.

\section{EL SEGUNDO EMPERADOR EN MÉXICO, MAXIMILIANO DE HABSBURGO.}

Maximiliano llegó a México el 28 de mayo de 1864, y en Veracruz leyó la siguiente proclama: "Mexicanos: iVosotros me habéis deseado! Vuestra noble nación, por una mayoría espontánea, me ha designado para velar de hoy en adelante sobre vuestros destinos. Yo me entrego con alegría a ese llamamiento" ${ }^{3}$. Claramente Maximiliano ignoraba los acontecimientos que envolvían a México, visiblemente engañando bajo la influencia de José Manuel Hidalgo, un fanático monárquico, que hizo pensar a Maximiliano que el sería la solución de los problemas de México.

Maximiliano salió para la Ciudad de México, donde hizo su entrada el 12 de junio de ese mismo año. Una vez instalado su gobierno, inició una política que no gustó a los conservadores, pues formó su ministerio con los señores Fernando Ramírez, Pedro Escudero y Echánove y Juan D. Peza, todos ellos liberales moderados. Maximiliano parecía más un conciliador, pensó en hacer desaparecer el odio de los partidos y atraer a todos a colaborar con él. Concedió una amnistía para los delitos políticos y recomendó a los gobernadores de los estados una actitud conciliadora con los adversarios de la monarquía. También decretó que se trabajara los domingos y días festivos. Deseando ampliar la acción de la prensa,

\footnotetext{
${ }^{3}$ Vicente Riva Palacio, México a través de los siglos, t. 10, p. 170.
} 
Maximiliano dispuso acabar con la censura previa; todo individuo podía emitir libremente sus opiniones sobre los actos oficiales para manifestar los inconvenientes de los mismos ${ }^{4}$.

Para agosto de 1864, la mayor parte del país estaba ya ocupada por las tropas francesas, el apoyo de Napoleón III hacia el nuevo monarca era visible, por otro lado, el grupo del presidente Benito Juárez se encontraba en Monterrey. Ahí, Juárez tuvo noticias de que los invasores preparaban un avance sobre esa ciudad de Monterrey, así que decidió que su familia marchara hacia Nueva York, bajo el cuidado de Pedro de Santacilia, un cubano que se casó con una de sus hijas. El día 15, el presidente Juárez logró salir con rumbo a Coahuila, un día después los franceses tomaron Monterrey para luego avanzar sobre Saltillo. A salto de mata, el presidente Juárez tuvo que emprender la retirada hacia Chihuahua, en la frontera del país, donde arribó el 12 de octubre, siendo recibido con las mayores muestras de consideración.

Para fines de 1864 el Imperio de Maximiliano, al igual que las Leyes de Reforma dadas por la República, nacionalizó los bienes del clero y suprimió el pago de obvenciones parroquiales. También decretó la ley de libertad de cultos y la ley de prensa; ambas leyes se encuentran en el Estatuto Provisional del Imperio. Todo parecería apuntar que la causa del Imperio estaba próxima a consumar su triunfo sobre la República. El Imperio ya no tenía más apoyo que el del ejército francés, pero éste sólo, era dueño del terreno que pisaba, sin que nada pudieran hacer las poblaciones ni los defensores del nacionalismo.

En enero de 1865, el Imperio publicó un decreto según el cual las bulas y breves papales no podían ser publicadas y ejecutadas sin el Exequátur imperial, caso contrario de lo que hizo Juárez con la Ley sobre libertad de cultos del 4 de diciembre de 1860, que en su artículo. 5 daba independencia a las sociedades religiosas para arreglar sus asuntos sin que se incida en falta o delito previsto por la ley; afirmaba que no hay obligación, pena o coacción "de ninguna especie" en materias espirituales; afirmaba también, que "la manifestación de las ideas sobre puntos religiosos, y la publicación de bulas, breves, rescriptos, cartas pastorales, mandamientos y cualquiera escritos que versen también sobre esas materias, son cosas en que se gozará de plena libertad, a no ser que por ellas se ataque el orden, la paz o la moral pública, o la vida privada o de cualquier otro de los derechos de tercero".

Ante la creencia de que la migración, sobre todo la europea, era una medida necesaria para reactivar la economía, Maximiliano promulgó una Ley de inmigración, el 5 de septiembre de 1865. Bajo la idea de que México requería colonos para incrementar la población productiva del país e inyectar capitales a la economía; se dieron todas las facilidades a los inmigrantes de cualquier nacionalidad. También, promulgó la Ley de instrucción pública del Imperio, en ella estableció la enseñanza religiosa en manos de los sacerdotes de los diversos cultos, bajo la supervisión del Estado. Asimismo, en 1866 se difundió el Reglamento para los

\footnotetext{
${ }^{4}$ Lilia Díaz, Historia general de México, “El liberalismo militante”, Colegio de México, 2000, p. 618-619.
} 
servicios de honor y ceremonial de la corte ${ }^{5}$, en donde a través de un ceremonial cortesano estrictamente reglamentado, intentaba infundir dignidad y decoro al gobierno imperial que el encabezaba ${ }^{6}$, ese texto vale la pena revisarlo en otra ocasión.

Por otra parte, el presidente Juárez, en uso de las facultades extraordinarias de las cuales estaba investido, emitió un decreto el 8 de noviembre de 1865, declarando prorrogado su mandato, en virtud de la imposibilidad de convocar a elecciones en aquellas condiciones. El decreto provocó protestas de algunos grupos liberales que apoyaban al presidente de la Suprema Corte, el general González Ortega, que de acuerdo con la Constitución del 57, debería fungir como presidente interino. Muchos de los liberales como Manuel Ruiz, Epitacio Huerta y Guillermo Prieto, decían que Juárez estaba cometiendo un Golpe de Estado. Pero la gran mayoría de los liberales, como Mariano Escobedo, Porfirio Díaz y Ramón Corona, aceptaron esta medida, tanto porque Juárez estaba investido de facultades extraordinarias por el propio Congreso como por que era la única resistencia a la intervención francesa y al Imperio ${ }^{7}$.

A mediados de diciembre de 1865, los franceses tornaron a Chihuahua obligando a Juárez a salir rumbo a la frontera en Paso del Norte, hoy Ciudad Juárez. Se corrió un rumor en el cual se decía que Juárez había abandonado el país y por lo tanto, ya no había causa para seguir luchando, sin embargo no fue así; pese a que en este período el presidente Juárez vivió días difíciles, ya que no tenía recursos para sostenerse en la lucha.

El contexto internacional provocó cambios en la situación particular de México, en enero de 1866 Napoleón III comunicó su decisión de retirar a su ejército de México, el papel de los Estados Unidos sería clave en el retiro paulatino de las tropas francesas. Para octubre, los franceses, ya habían dejado las ciudades de Matamoros, Monterrey, Tampico y Saltillo.

La pérdida de la protección francesa fue para Maximiliano un golpe muy duro, ya que empezó a desconfiar de todos los que le rodeaban, por lo que cambió al representante en Francia, el señor José Manuel Hidalgo, enviando en su lugar a Juan N. Almonte, quien llegó a París el 14 de mayo, para pedir que el ejército francés se quedara tres años más en México.

A pesar de la debilidad de las fuerzas nacionales en relación con las francesas, el país nunca fue ocupado ni dominado plenamente; por lo tanto, no se podía tener el consenso de

\footnotetext{
${ }^{5}$ Reglamento para los servicios de honor y ceremonial de la corte, México, Imprenta J. M Lara calle de la Palma N. 4, 1866.

6 Pani Erika, "el proyecto de estado de Maximiliano a través de la vida cortesana y del ceremonial público", en Historia Mexicana, XLV:178 (octubre-diciembre), 1995, p. 437.

${ }^{7}$ Art. 82 de la Constitución de 1857, señala de un modo explícito que al término del período ordinario cese el Presidente de la República, sea cual fuere el motivo que impida la elección del sucesor, o la presencia oportuna del electo, y manda que entre tanto el Poder Supremo se deposite irremisiblemente en el Presidente de la Suprema Corte.
} 
todo el país, ya que había ciudades y pueblos que por meses eran sometidos por los franceses y después retomados por los liberales.

La tutoría que el jefe del ejército francés ejerció sobre el imperio resultó el más grande obstáculo para la consolidación del gobierno. Maximiliano, en 1863, junto con los emigrados, preparó un anteproyecto de Constitución, el cual nunca se aplicó debido por la-situación económica en que se encontraba México; en cambio los dictados de Napoleón III se obedecían como si fuera la Ley Suprema, y se le imponía al emperador Maximiliano.

Mientras tanto el presidente Benito Juárez salió del Paso del Norte, el 10 de junio de 1863, para llegar a Chihuahua una semana más tarde. El 10 de diciembre de 1866 continúa su ruta hacía el sur, deteniéndose en Durango el 26 de diciembre, posteriormente salieron para Zacatecas, a donde llegaron el 22 de enero de 1867. A medida que las fuerzas invasoras abandonaban el país, los republicanos recuperaban el terreno perdido.

Para febrero ya se encontraban en San Luis Potosí, mientras que el ejército imperial se encontraba en Querétaro, con Maximiliano al frente del mismo. Con Márquez en el estado Mayor, Miguel Miramón como jefe de la infantería, Tomas Mejía como jefe de la caballería, Ramírez Arellano como comandante de artillería y Ramón Méndez como jefe de la brigada de reserva, harían frente al avance republicano en Querétaro, con diez mil hombres efectivos.

En mayo de 1867 las fuerzas republicanas sitiaron Querétaro, capturando así a Maximiliano y a sus generales. El 15 de mayo arrojaron los sitiadores varios proyectiles huecos, que llevaban dentro el siguiente telegrama:

General Díaz: la plaza de Querétaro ha caído en nuestro poder esta mañana a las seis de ella. Daré a usted pormenores. Maximiliano, con las fuerzas que tenía en la plaza, así como los jefes de ella, armas municiones, artillería y todo, ha caído en nuestro poder, rindiéndose a discreción. [Firma] Alcérrica ${ }^{8}$.

Nos dice otra fuente que:

El 15 de mayo se presentó al general Corona un ayudante del general Escobedo participándole que el convento de la Cruz había caído en poder de los republicanos. En aquellos momentos notó el general Corona que con dirección a su línea se desprendía de dicho cerro un oficial con bandera blanca, el general se adelantó a su encuentro seguido de su escolta, el oficial venia de parte de Maximiliano para decir que el emperador se rendía, así pues, el emperador acompañado de varios de sus

\footnotetext{
${ }^{8}$ Francisco de Paula de Arrangoiz, México desde 1808 hasta 1867, p. 864.
} 
generales, como Mejía y Castillo, se entregaban a la fuerza republicana comandadas por el general en jefe Escobedo?.

El ministro de guerra envió una carta al general Escobedo, previéndole que se procediese a juzgar a Maximiliano y a sus generales Miramón y Mejía, con entero arreglo a los artículos 60 al 11으, incluso de la Ley de 25 de enero de 1862, que condenaba a muerte a todo aquel que atentara contra la independencia nacional.

El 14 de junio de 1867 se le condenó a muerte haciendo saber a Maximiliano de este hecho el coronel Manuel Aspiroz, quien desempeñó el cargo de fiscal. Múltiples solicitudes de indulto recibió Juárez tanto como de gobernantes como de intelectuales la madrugada después de consumado el fusilamiento.

El 15 de julio de 1867, Juárez arribó a la ciudad de México en donde la gente lo vitoreó, completando así el triunfo de la República. Una vez establecido el Congreso, fue reelecto Juárez como presidente constitucional de México, el 22 septiembre de 1867. En este período presidencial poco pudo hacer Juárez a favor del desarrollo del país, ya que varios cabecillas fueron levantándose en armas, como fue el caso de Marcelino Villafaña en Yucatán a principios de 1868; los generales Francisco Aguirre y Pedro Martínez, en San Luis Potosí, en diciembre de 1869; el general Trinidad de la Cadena, en Zacatecas, el mismo año; el 2 de mayo de 1871 se pronunciaron Calleja y Molina en Tampico, todas estas sublevaciones fueron controladas. Pero fue difícil para el presidente Juárez gobernar un país que no tenía tantos recursos económicos, ya que venía de una etapa en donde la guerra había mermado el erario público.

\section{ANÁLISIS DEL CERMONIAL, PARA LA FIESTA NACIONAL DEL 16 DE SEPTIEMBRE DE 1866}

Durante el segundo Imperio, Maximiliano promovió la identidad nacional a través de los festejos de la independencia, fue el primer gobernante que dio el Grito desde Dolores, Guanajuato en 1864.

Mexicanos: más de medio siglo tempestuoso ha transcurrido desde que esta humilde casa, del pecho de un humilde anciano, resonó la gran palabra de Independencia, que retumbó como un trueno del uno al otro

océano por toda la extensión de Anáhuac, y ante la cual quedaron

aniquilados la esclavitud y el despotismo de centenares de años. Esta palabra, que brilló en medio de la noche como un relámpago, despertó a toda la nación de un sueño ilimitado a la libertad y a la emancipación; pero

\footnotetext{
${ }^{9}$ Vicente Riva Palacio, Op. cit., p. 379. Miramón fue hecho prisionero en la casa del doctor Liceo, adonde había ido a curarse de una herida que recibió en la cara la madrugada del 15 de mayo.
} 
todo lo grande y todo lo que está destinado a ser duradero se hace con dificultad y a costa de tiempo.

Como lo referimos, el Imperio de Maximiliano fue prolífico respecto a la generación de leyes y normas, en particular llama nuestra atención el Reglamento para los servicios de honor y ceremonial de la corte, publicado en 1866, el cual incluía un ceremonial de la fiesta nacional del 16 de septiembre, la fiesta más importante a nivel nacional.

El ceremonial fue publicado en el Reglamento para los servicios de honor y ceremonial de la corte de 1866 y en el Diario del Imperio, el día miércoles 12 de septiembre de $1866^{10}$, firmado dicho decreto por el primer secretario de las ceremonias don Pedro C. Negrete, en él destacan algunas modificaciones que tuvieron que hacerse debido a la ausencia de la Emperatriz Carlota, quien había salido hacia Europa a pedir ayuda al emperador Napoleón y después a Roma.

De esta manera, la fiesta nacional se celebraría con un protocolo al estilo europeo, una paradoja, pues se tendría la conmemoración de la independencia de España al estilo de la corte francesa y una verbena popular. Maximiliano el monarca austriaco, reivindicando la gesta de Miguel Hidalgo, el pueblo mexicano celebrando su independencia bajo el gobierno del usurpador europeo.

El ceremonial recogía se dividió en 43 pasos en donde destacamos los siguientes:

1. Al romper el alba, la solemnidad del día se amaneciera con una salva de artillería tirada en la ciudadela.

2. A las cinco de la mañana todas las músicas militares presentes en la capital, se reunirán en la Plaza Mayor, donde juntas tocarán el himno nacional... hasta las seis...

3. A las siete y media de la mañana, las personas que componen el Gran Sequito estarán reunidas en Palacio...

4. A las ocho de la mañana, el Primer Secretario de las Ceremonias entrara a la Sala de Audiencias del Emperador, y pondrá en conocimiento del Emperador que todo está dispuesto para la ceremonia.

5. Se formará inmediatamente el Gran Sequito, como sigue:

- Secretarios de las ceremonias

- Oficiales de Órdenes

- Oficiales de la Guardia Palatina

${ }^{10}$ El Diario del Imperio, miércoles 12 de septiembre de 1866, Num. 510, México imprenta imperial. 
- Capellanes Honorarios de la Corte

- Capellanes de la Corte

- Caballerizos Honorarios

- Médicos Consultores de la Corte

- Médicos de la Corte

- Empleados Superiores de la Corte

- Director de la intendencia General de Lista Civil

- Primer Médico del Emperador

- Primer Capellan de la Corte

- Ayudantes de Campo

- Caballerizos

- Chambelanes

- Generales de División

- Grandes Cruces de Guadalupe

- Consejeros Honorarios de Estado

- Consejeros de Estado

- Grandes Cruces del Águila Mexicana

- Presidente del Tribunal de Cuentas

- Ministro Honorario

- Ministros

- Presidente del Consejo de Estado

- Chambelan Marques de Vivanco

- El Emperador

- Chambelan de Servicio

- Ayudante de Campo de Servicio

- Oficial de la Guardia Palatina de Servicio

- Oficial de Órdenes de Servicio

14. El Emperador será recibido en la puerta del centro de la catedral por el Arzobispo y el cabildo. El agua bendita le será presentada por el arzobispo, que se incorporará al Séquito con el Cabildo que le acompaña, tomando lugar entre el presidente del consejo de estado y el chambelán Marques Vivanco. 
15. Al llegar al altar, el emperador se dirigiría al Trono, colocado del lado del evangelio...

16. El Arzobispo entonará él Te Deum.

17. Los repiques de campanas y las salvas de artillería anunciaran los momentos más solemnes de la festividad.

21. El emperador regresará con el gran Sequito a Palacio, y atravesando los mismos salones que a la salida...

23. Cuando todo esté listo para la recepción el Emperador acompañado del pequeño sequito se trasladara a la Galería de Iturbide y subirá al estrado del Trono.

24. El Presidente del Consejo de Estado pronunciara un discurso alusivo a la circunstancia.

25. El emperador se dignara a contestar.

26. En este momento tendrá lugar la distribución de condecoraciones y medallas.

34. En seguida tendrá lugar el desfile de las Corporaciones en el orden siguiente:

- Los Ministros

- El Presidente del Consejo de Estado y los Consejeros efectivos y honorarios

- El Mariscal Comandante el Jefe con la oficialidad

- El Vicepresidente del Supremo Tribunal de Justicia y los Magistrados de este.

- El Presidente Tribunal de Cuentas

- El Abogado General con los procuradores y abogados generales del Tribunal Supremo de Justicia

- Las Grandes Cruces de Guadalupe

- El presidente del Tribunal Superiores del Departamento con los magistrados del mismo

- El arzobispo con el clero

- El presidente de la academia Imperial de Ciencias y Literatura con las academias

- Los Subsecretarios de los Ministerios con los empleados de estos y de las oficinas que dependen de ellos en el orden siguiente:

○ Negocios Extranjeros y Marina

○ Gobernación y Fomento 
- Justicia, Instrucción Pública y Cultos

○ Guerra

○ Hacienda

- El Prefecto Departamental con el Consejo del Departamento

- El Alcalde Municipal con el Ayuntamiento

- Los Presidentes de los Tribunales

- Los Condecorados con las Ordenes y medallas del Imperio

- Los veteranos de la independencia

36. Terminado el desfile el Emperador se retirará a sus habitaciones...

\section{Por la Tarde}

40. El emperador recorrerá la ciudad en carruaje descubierto, acompañado del pequeño servicio de honor, para visitar los principales puntos donde tienen lugar las festividades públicas.

El traje para este paseo será el de mañana

A las tres y media en la Plaza del Paseo Nuevo, corrida de toros. A la misma hora, funciones dramáticas en los teatros: Principal, Oriente y Nuevo México.La entrada será gratuita y sin billetes

Desde las dos de la tarde, habrá maromas en las plazas de San Fernando, San Lucas, Santo Domingo y San Juan de Dios.

Palos ensebados, con prendas de ropa y monedas en las Plazas de Las Vizcaínas, Santa Ana y San Pablo.

Música y globos en los paseos.

\section{Por la Noche}

41. A las cinco y media habrá en Palacio un gran Banquete de Corte.

42. A las siete y media, en la Plaza de Armas, fuegos artificiales.

43. Las músicas de los cuerpos de guarniciones, tocaran hasta las diez de la noche.

Sin embargo, como señalamos al principio, existieron algunas diferencias con lo establecido en el Reglamento y el Diario del Imperio, debido a la ausencia de la Emperatriz, se 
pueden observar en ese Reglamento en su Capítulo $\mathrm{VI}^{11}$, sobre la Fiesta del Aniversario de la Independencia de acuerdo a los siguientes puntos.

- El día de la Fiesta de la Independencia, a las siete y media de la mañana, estarán reunidas en Palacio las personas que componen la primera y segunda categoría y el Gran Séquito.

- Las primeras, que habrán sido invitadas por el Gran Mariscal de la Corte, en la forma ya descrita, entrarán a Palacio y por la escalera de la Emperatriz, la Sala de Yucatán y la Galería de Pinturas, se trasladarán a la Sala de Audiencias del Emperador.

- El Gran Séquito, convocado por el Gran Mariscal de la Corte y por el Gran Maestro de Ceremonias, según las categorías de las personas que lo componen, se juntará en la Galería de Pinturas. La entrada a los Salones habrá sido por la escalera del Emperador, la Galería de la Guardia Palatina y la de Iturbide.

- A las ocho de la mañana, el Gran Maestro de Ceremonias avisará al Gran Mariscal de la Corte, que todo está dispuesto, y éste entrará en la Sala de Carlos V, en la que los Emperadores se hallarán y lo pondrá en su conocimiento, retirándose en seguida a la Galería de Pinturas.

- Los Emperadores saldrán entonces de la Sala de Carlos V, y se dirigirán a la Sala de Audiencias del Emperador, en la que están esperando las personas que forman parte de la primera y segunda categoría, y con ellas entrarán a la Galería de Pinturas.

- Se formará inmediatamente el Gran Séquito como sigue:

1. Secretarios de las Ceremonias.

2. Oficiales de Órdenes.

3. Oficiales de la Guardia Palatina.

4. Capellanes honorarios de la Corte.

5. Capellanes de la Corte.

6. Caballerizos honorarios.
28. Gran Mariscal de la Corte.

29. Príncipes de Iturbide.

30. Collares del Águila Mexicana.

31. Cardenales.

32. Príncipes Imperiales.

EL EMPEEADOR.

${ }^{11}$ Reglamento para los servicios de honor y ceremonial de la corte, México, Imprenta J. M Lara calle de la Palma N. 4, 1866, pp. 249 a 258. 
7. Médicos consultantes de la Corte.

8. Médicos de la Corte.

9. Empleados Superiores de la Corte.

10. Primer Médico del Emperador.

11. Primer Capellán de la Corte.

12. Generales de Brigada Ayudantes de Campo.

13. Caballerizos.

14. Chambelanes.

15. Generales de División.

16. Generales de División Ayudantes de Campo.

17. Grandes Cruces de Guadalupe.

18. Consejeros honorarios de Estado.

19. Consejeros de Estado.

20. Grandes Cruces del Águila Mexicana.

21. Presidente del Tribunal de Cuentas.

22. Ministros.

23. Presidente del Supremo Tribunal de Justicia.

24. Presidente del Consejo de Estado.

25. Presidente del Consejo de Ministros.
33. Gran Maestro de Ceremonias.

34. Ayudante de Campo General.

35. Gran Chambelan.

36. Caballerizo Mayor.

37. Capitán de la Guardia Palatina.

38. Chambelan de servicio.

39. Gran Chambelan de la Emperatriz.

LA. EMPEEATEIZ.

40. Dos Damas de Palacio de servicio.

41. Princesas Imperiales.

42. Princesas de Iturbide.

43. Grandes Cruces de San Carlos.

44. Dama Mayor.

45. Damas de Palacio.

46. Damas de Honor. 
26. Intendente General de la Lista Civil.

27. Limosnero Mayor

- En esta forma los Emperadores saldrán de la Galería de Pinturas, y atravesando las de Iturbide y de la Guardia Palatina, bajarán por la Escalera del Emperador para tomar la Puerta del Centro de Palacio, y se dirigirán a la Catedral.

- En la Galería de la Guardia Palatina estará formada la Guardia Palatina y la servidumbre de Palacio en la forma siguiente:

- 1 Un destacamento de la Guardia Palatina.

- 2 Mozos de espuela.

- 3 Caballerizos picadores.

○ 4 Lacayos.

○ 5 Ungieres.

○ Ayudas de Cámara.

- Al llegar los Secretarios de las Ceremonias, al primer compartimiento de la Galería de Iturbide, el destacamento de la Guardia Palatina y la servidumbre bajará la Escalera del Emperador.

- Otro destacamento de la Guardia Palatina se colocará a derecha e izquierda de los Emperadores, cuando pasen por la Galería de la Guardia Palatina, y un tercer destacamento de esta Guardia marchará después del Gran Séquito.

- La guarnición de México estará formada con anticipación en la Plaza de Armas, y al avistar a los Emperadores, las tropas presentarán las armas, batirán marcha y las músicas tocarán el himno nacional.

- El Gran Séquito se dirigirá al atrio de la Catedral. Una alfombra y un toldo estarán tendidos en el trayecto.

- Todos los funcionarios públicos que no formen parte del Gran Séquito, se encontrarán desde las siete y media de la mañana, en la Catedral, en los sitios que de antemano les estarán reservados.

- La valla que forman las tropas se prolongará por dentro del Templo, hasta detrás del altar mayor.

- Al llegar a la puerta del centro de la Catedral el destacamento de la Guardia Palatina entrará en ella, y la servidumbre de Palacio, quedándose fuera, formará valla al paso del Gran Séquito, y entrará en la Catedral después de él, permaneciendo al pie de ella. 
- Los Emperadores serán recibidos en la puerta principal de la Catedral por el Arzobispo y el Cabildo. El agua bendita Les será presentada por el Arzobispo, que se incorporará con el Cabildo que le acompaña al Séquito, tomando lugar entre el Limosnero Mayor y el Gran Mariscal de la Corte.

- Al llegar al altar, los Emperadores se dirigirán al Trono colocado del lado del Evangelio, y las personas del Gran Séquito a los asientos que tienen reservados.

- El Arzobispo entonará él Te Deum.

- A su conclusión, se volverá a formar inmediatamente el Gran Séquito, y los Emperadores, acompañados de éste, saldrán de la Catedral, en la misma forma que a su entrada.

- La servidumbre de Palacio volverá a tomar la cabeza del Séquito en la puerta de la Catedral.

- El Arzobispo y el Cabildo acompañarán a los Emperadores hasta la puerta principal de la Catedral.

- Los Emperadores regresarán con el Gran Séquito hasta la puerta del centro de Palacio

- El Emperador, Su Casa Militar y las personas que hubiere mandado citar para acompañarle, montarán a caballo en el patio de Honor.

- La Emperatriz durante este tiempo regresará a la Galería de Iturbide y se colocará en el balcón principal de Palacio con las Princesas Imperiales y las Princesas de Iturbide. Su comitiva se pondrá en los otros balcones. La Guardia Palatina y la servidumbre de Palacio se detendrán en la Galería de la Guardia Palatina.

- El Emperador saldrá de Palacio y se quedará delante de la puerta del centro. Su comitiva se quedará detrás, conforme lo arregle el Ayudante de Campo General.

- Entonces tendrá lugar el desfile de las tropas de la guarnición.

- Después de terminado, el Emperador entrará a Palacio con su comitiva y se trasladará por la escalera de la Emperatriz, la Sala de Yucatán y la Galería de Pinturas, a la Sala de Audiencias para reunirse con la Emperatriz, que después del desfile se habrá retirado a ella.

- La Casa Militar del Emperador se quedará con la Corte en la Galería de Pinturas. Las demás personas que, sin ser de la Corte pertenecen al Gran Séquito, ocuparán los sitios que les estén designados para la recepción.

- Entonces tendrá lugar la gran recepción de las autoridades, en la que se observará el ceremonial fijado para estas solemnidades, adaptándole a la circunstancia presente. (Capítulo quinto, sección primera).

- Cuando los Emperadores hayan subido al estrado del Trono, y que todas las personas que les acompañan estén en sus puestos respectivos, el Presidente del Consejo de Ministros o en su defecto o falta, el Presidente del Consejo de Estado, 
pronunciará un discurso propio de la circunstancia, que los Emperadores oirán de pie.

- A la conclusión del discurso, los Emperadores se sentarán en el Trono, y el Emperador se dignará contestar al Ministro.

- Cuando el Emperador lo disponga, distribuirá, en este momento, condecoraciones y medallas; en este acto se seguirá el ceremonial fijado.

- En seguida, tendrá lugar el desfile de las corporaciones, en el orden prescrito en el ceremonial de las grandes recepciones, ya citado.

- El traje de los concurrentes a la solemnidad será el siguiente:

- Los Collares del Águila Mexicana y los Grandes Cruces de Guadalupe se pondrán los respectivos Collares de estas órdenes.

- Los Señores que tengan uso de uniforme estarán de gran gala; los que no lo lleven, de frac negro, corbata blanca y condecoraciones.

- Las Señoras de vestido escotado, alhajas y condecoraciones.

- Por la tarde, los Emperadores recorrerán la ciudad, en carruajes descubiertos, acompañados del pequeño servicio de Honor, para visitar los principales puntos, donde tienen lugar las fiestas populares. El traje para este paseo será el de mañana; las Señoras con vestido alto.

- A las siete y media de la noche, habrá fuegos artificiales en la Plaza de Armas.

- A las ocho y media de la noche, tendrá lugar una función de gran gala, en el Teatro Imperial, observándose en ella el reglamento de estas funciones. (Capítulo sétimo, sección quinta). La concurrencia se convidará por el Gran Maestro de Ceremonias, conforme a la Ley de Precedencias.

- Los momentos más solemnes de la festividad del día, se anunciarán con salvas de artillería y repiques de campanas.

\section{FUNCIONES DEL GRAN MAESTRO DE CEREMONIAS Y EL SERVICIO DE LAS CEREMONIAS.}

Por otro lado, el Reglamento para los servicios de honor y ceremonial de la corte establece dentro de su estructura, un capítulo sobre las funciones del Gran Maestro de Ceremonias en la corte de Maximiliano, en este breve apartado veremos algunas de sus obligaciones para que el lector pueda observar la dedicación y el gran trabajo, de quien quizá sea uno de los personajes menos estudiados, pero de los más importantes en el ceremonial de la corte de Maximilano, el Gran Maestro de Ceremonias encargado al señor Francisco Mora 
Serapio ${ }^{12}$, este sería de acuerdo con el reglamento la tercera Gran Dignidad de la Corte. Prestaría juramento ante el Emperador y ocupara el lugar que se le asigna en el ceremonial.

Francisco Mora, el gran maestro de ceremonias, era quien disponía todo el ceremonial, pues conocía perfectamente todas las prácticas de las cortes europeas en cosas análogas por haber pasado la mayor parte de su vida en Paris, Francia.

Mora después de arreglar su ceremonia, la presentaba a la Emperatriz con quien discutía los puntos más esenciales y ya aprobados éstos por la soberana se presentaba el programa completo al emperador ${ }^{13}$.

Son las obligaciones del Gran Maestro:

i. El ceremonial de la Corte.

ii. Las presentaciones civiles.

iii. Las invitaciones.

iv. Los bailes, fiestas y conciertos.

v. Decidir sobre las cuestiones de precedencia y rango de la Corte,

vi. Decidir sobre las mismas cuestiones, respecto del cuerpo Diplomático,

vii. La dirección de los Teatros Imperiales.

viii. Los duelos de la Corte.

Arregla los proyectos de las ceremonias, determina el lugar y el tiempo en que deban celebrarse, el orden que haya de seguirse y las formalidades que deban observarse, asignando a cada cual el sitio o asiento que le corresponda con arreglo a las localidades y al orden de procedencia combinado con las necesidades del servicio, indica las disposiciones y trabajos que exigen los ceremoniales.

12 Diplomático mexicano, ingreso en el servicio el 5 de octubre como oficial de Legación en Paris, el 28 de noviembre de 1846, ascendió a secretario. El 18 de enero de 1851 quedo como encargado de negocios ad interim. 1853 presento sus credenciales al gobierno de Napoleón, después fue maestro de ceremonias en el 2o imperio, del Gran Maestro de Ceremonias de Maximiliano, sabemos por mención del libro de su Secretario Particular José Luis Blasio, Maximiliano Intimo el emperador mexicano y su corte.

${ }^{13}$ Blasio, José Luis, Maximiliano Intimo el emperador mexicano y su corte, librería de la V Da de C. Bouret, parís México, 1903, pp. 50 y 51. 
Cuando se aproxima la época de alguna de las fiestas nacionales o de Corte, el Gran Maestro de Ceremonias presenta a la aprobación del Emperador los proyectos del ceremonial que ha de observarse en ella.

Si la fiesta tiene a la vez el carácter de nacional y de Corte, el Gran Maestro de Ceremonias pedirá al Ministro de Gobernación un proyecto de programa, para adaptarlo en seguida a lo que determina el ceremonial de la Corte. Si la fiesta es puramente religiosa y ha de tener lugar fuera de los Palacios o Sitios Imperiales, se dirigirá con el mismo fin a la autoridad religiosa.

Cuando sea necesario, para arreglar las formalidades de una gran ceremonia, conferenciar con los otros empleados superiores de la Corte o del Gobierno, la conferencia se celebrará en el despacho del Gran Maestro de Ceremonias.

Después de aprobado el proyecto por el Emperador, el Gran Maestro de Ceremonias escribe su firma el ceremonial.

Si la fiesta es a la vez nacional y de Corte, remite al Gran Mariscal de la Corte el número necesario de ejemplares del ceremonial, para que éste pueda enviarlos en la forma descrita a las personas de la primera, segunda y tercera categoría. Dirige también ejemplares del ceremonial a las Grandes Dignidades de la Corte, al Arzobispo, al General Comandante de la División, al Prefecto Departamental y al Alcalde Municipal. Comunica a cada jefe de los servicios de la Corte lo que debe alistar de guardias, ujieres, lacayos, efectos, carruajes y caballos.

Si la fiesta es puramente de Corte, remite el número necesario de ejemplares del ceremonial al Gran Mariscal de la Corte, para que éste, en la forma acostumbrada los envié a los Príncipes Imperiales, a las personas de la segunda categoría que pertenezcan a la Corte y á los Príncipes de Iturbide. Dirige también ejemplares a las Grandes Dignidades de la Corte, avisándoles lo que deben alistar de guardias, ujieres, lacayos, efectos, carruajes y caballos.

En ambos casos, cada Gran Dignidad remitirá un ejemplar del ceremonial, a cada una de las personas de los servicios de Honor que dependan de ella.

Al Gran Maestro de Ceremonias, toca prescribir el traje con que se debe asistir a las solemnidades de la Corte, de- terminando si es de gran gala, de media gala 6 de traje civil. Fijará también el de la servidumbre de Palacio.

Le corresponde mandar al dibujante de las ceremonias que haga los diseños necesarios para la disposición de las grandes solemnidades, cuyos trabajos someterá a la aprobación del Emperador. 
El día de la fiesta, el Gran Maestro de Ceremonias vigilará el puntual cumplimiento de todas las partes del ceremonial, permaneciendo mientras dure el acto, cerca del Emperador para recibir sus órdenes, cuando el caso lo requiera.

Cuando las grandes corporaciones del Estado deban concurrir al Palacio Imperial, ya sea en cuerpo o por medio de diputaciones, se dirigirán (previa la autorización del Ministro de quien dependan) al Gran Maestro, para que impetre del Emperador las órdenes correspondientes a esta recepción.

Obtenida la venia del Emperador, el Gran Maestro de Ceremonias las introduce, las anuncia y las presenta.

Es el intendente de los Teatros de la Corte y de la Música de Cámara.

Toma las órdenes del Emperador sobre todo lo que se relaciona con los espectáculos y conciertos dados en la Corte y con el servicio de la Música de Cámara.

Recibe las órdenes del Emperador sobre las funciones de Teatro o concierto a las que se digne asistir, y se encargará de tomar todas las disposiciones necesarias para cumplimentar las órdenes que haya recibido. Dispondrá que la Lista Civil entregue la cantidad que juzgue oportuna.

El Director de la Música de Cámara le presenta para su aprobación los ajustes eventuales de artistas que deben contratarse.

El Gran Maestro de Ceremonias forma también el ceremonial para la recepción de los Embajadores y Ministros Plenipotenciarios, Enviados Extraordinarios extranjeros, acreditados cerca del Emperador, y después de haber sido aprobado por el, lo envía al Gran Mariscal de la Corte.

Recibe las visitas que los Enviados Extraordinarios y Ministros Plenipotenciarios le hagan, antes de presentar al Emperador sus credenciales, y en cuanto el Ministro de Negocios Extranjeros le haya informado de que el Emperador recibirá a estos representantes, les devolverá la visita y les informará del día y de la hora que el Emperador haya designado para la presentación de sus credenciales.

El Gran Maestro pondrá en conocimiento del Ministro de Negocios Extranjeros la decisión del Emperador.

El día de la recepción, el Gran Maestro vigila que todas las formalidades indicadas en el Ceremonial se lleven á debido efecto, para lo cual dan las instrucciones necesarias a todas las personas de servicio. 
Cuando la audiencia concedida a algún diplomático extranjero es secreta, el Gran Maestro le introduce al Salón de Audiencias del Emperador a su presencia y se retira a la Sala contigua.

Cuando el Emperador ofrezca bailes, comidas, fiestas o conciertos, o en cualquier otra función nacional o de Corte, las invitaciones se harán a nombre del Emperador por medio del Gran Maestro de Ceremonias, menos en los casos y a las personas que deben ser convidadas por el Gran Mariscal de la Corte.

En las comidas, el Gran Maestro de Ceremonias le preguntaba al Emperador para saber qué personas se colocarán en la mesa al lado de los Emperadores y de los Príncipes Imperiales, y fijará después el lugar de las demás personas convidadas.

Además, recibe el parte que cada jefe de servicio le comunica sobre las ocurrencias de su dependencia, con objeto de hacer las constar en el Diario de la Corte. Todos los empleados del servicio a cuyo frente se halla, prestan juramento en sus manos.

También, somete al Ministro de la Casa Imperial, por conducto del Intendente General de la Lista Civil, las propuestas de los nombramientos de su incumbencia.

El Gran Maestro de Ceremonias no ejercerá cerca de la Emperatriz las funciones de su cargo, sino cuando el Emperador lo mande. En lo general, la Dama Mayor y el Gran Chambelán de la Emperatriz quedan encargados del desempeño de ellas.

El Gran Maestro de Ceremonias cuida de que los Secretarios levanten las actas de todas las fiestas, las firma y al fin de cada año las presenta al Emperador.

En su oficina, se llevarán los libros siguientes, con la mayor exactitud:

- De la correspondencia con los Emperadores.

- De las actas de las ceremonias, recepciones y fiestas de la Corte.

- El Diario de la Corte.

- De la correspondencia general.

- De los lutos de la Corte.

- De traducciones de ceremoniales de las cortes extranjeras.

- De las listas de los convidados a Palacio.

- De las direcciones de éstos, por orden alfabético.

El Gran Maestro de Ceremonias presenta al fin de cada año, al Intendente General de la Lista Civil, los presupuestos de gastos e ingresos de su departamento, así como el presupuesto para el año siguiente. 
Todos los trabajos interiores de su servicio están determinados y repartidos entre los Secretarios de las Ceremonias y los demás empleados de su oficina, por un reglamento especial.

Los gastos de correspondencia y otros de oficio del Gran Maestro de Ceremonias y de su departamento, se cargarán a la Lista Civil.

Dará parte al Gran Mariscal de la Corte, de todo lo que ocurra en el servicio de las Ceremonias.

El Gran Maestro de Ceremonias no podrá tratar en el desempeño de sus funciones, de ningún asunto extraño al servicio.

Solo podrá ver al Emperador cuando le llame y cuando haya pedido una audiencia.

Solo por escrito podrá comunicar con el Emperador.

Dice Erika Pani, respecto al Gran Maestro, el ceremonial de la corte se observaba con todo rigor, y no sabemos de ningún problema por confusión de precedencias o errores de etiqueta. Esto podía deberse a la habilidad del gran maestro de ceremonias, Francisco Mora, quien publicaba y repartía el ceremonial de cada evento con anterioridad ${ }^{14}$.

\section{PUNTOS FINALES}

Maximiliano tenía la convicción de poner orden en México en todas sus esferas, por eso el asunto de la creación de su corte era muy importante. Ya que con eso se tenían establecidas las funciones de cada una de las personas al servicio del monarca. Este orden además imponía las "buenas maneras", la belleza que debían tener los actos, pues estaban dedicados a Dios finalmente.

Se preocupó por sus habitantes y promovió como los mismos liberales, políticas progresistas que no fueron bien vistas por los grupos conservadores que teminaron dejándolo solo.

Muy ad hoc con sus orígenes monárquicos Maximiliano promovió la creación de una corte en México. Elementos del ceremonial establecido en su momento por Maximiliano perviven en las celebraciones recientes. La gala, el desfile, el compartir los alimentos u ofrecer una cena con personajes destacados de la política.

\footnotetext{
${ }^{14}$ Pani Erika, "el proyecto de estado de Maximiliano a través de la vida cortesana y del ceremonial público", op. Cit., P. 434
} 
Por otra parte el papel del Gran Maestro de Ceremonias no debe pasar desapercibido actualmente no hay un jefe de protocolo para asistir al titular del poder ejecutivo por lo que sería importante sugerir uno.

El gran maestro de ceremonias es la representación del orden, quien esté a cargo de este puesto debe conocer a la perfección la ceremonia, sus elementos, sus símbolos, sus tiempos precisos y su sentido.

El ceremonial establecido por Maximiliano colocaba en el centro del festejo de la independencia al gobernante y en una especie de pirámide al resto de los actores sociales, ninguno en igualdad.

Sin embargo, respecto a nuestro tema, podríamos pensar que la corte de Maximiliano abría el campo de acción de la política imperial, extendiéndolo hacia la esfera social. Los bailes, las comidas y las festividades, eran fiestas políticas, a las cuales asistía la elite de México. A través de estos eventos sociales los emperadores podían conocer a la sociedad mexicana y tratar de ser aceptados por ellos.

\section{BIBLIOGRAFÍA}

Arrangoiz, Francisco de Paula de, México desde 1808 hasta 1867, 4a ed. México, Porrúa, 1985. 966 p.

Blasio, José Luis, Maximiliano Intimo el emperador mexicano y su corte, librería de la V Da de C. Bouret, parís México, 1903.

El Diario del Imperio, miércoles 12 de septiembre de 1866, Num. 510, México imprenta imperial.

Egon Caesa, conde de Corti, Maximiliano y Carlota, México, Fondo de Cultura Económica, 1999.

JUÁREZ, Benito, Documentos, discursos y correspondencia, 15 Tomos, Prólogo de Jorge Tamayo, México, Ed. Secretaria del Patrimonio Nacional, 1971.

Magallón IbarRa, Jorge Mario, Proceso y ejecución vs. Fernando Maximiliano de Habsburgo, UNAM, México, 2005.

Riva PalACIO, Vicente, México a través de los siglos, T. 10, Ed. Cumbre, S.A., 1981.

Reglamento para los servicios de honor y ceremonial de la corte, México, Imprenta J. M Lara calle de la Palma N. 4, 1866.

RoEDER, Ralph, Juárez y su México, México, Ed. FCE, 1991. 
Pani Erika, "el proyecto de estado de Maximiliano a través de la vida cortesana y del ceremonial público", en Historia Mexicana, XLV:178 (octubre-diciembre), 1995, 523.

TAMAYO, Jorge L., Epistolario de Benito Juárez. México, FCE.1975.

VALADÉs, José C., El pensamiento político de Benito Juárez, México, Ed. Manuel Porrúa, S. A., S/F.

Historia del Pueblo de México, 3 vol., México, Editores mexicanos Unidos, S. A., 1967.

VV.AA., Historia general de México, "El liberalismo militante", México, Ed. El Colegio de México, 2000. 
